Check for updates

New York

Cite this as: $B M J$ 2021;372:n210 http://dx.doi.org/10.1136/bmj.n210 Published: 22 January 2021

\title{
Covid-19: Biden launches national plan based on "science and public health alone"
}

\section{Janice Hopkins Tanne}

President Joe Biden has warned that the US death toll from covid-19 may reach 500 ooo by this time next month. But on his second day in office he offered a 200 page national plan to combat the uncontrolled spread of SARS-CoV-2 and to rebuild the US public health infrastructure, calling it a wartime effort. ${ }^{1}$ Former president Donald Trump left planning to individual states.

Although the US has only $4 \%$ of the world's population, it has $25 \%$ of its covid-19 cases and $20 \%$ of deaths. More than 400000 Americans have died from covid-19, more than died during the second world war. As at 21 January the US had more than 24.5 million cases, the world's highest number, with 184754 new cases, 4367 new deaths, and 122700 people admitted to hospital. ${ }^{2}$

Biden said, "The honest truth is that we are still in a dark winter of this pandemic. It will get worse before it gets better." He called for all Americans to work together in a common purpose and cautioned that it would take months to "get out of this mess."

He said, "The national strategy will be driven by scientists and public health experts who will regularly speak directly to you, free from political interference as they make decisions strictly on science and public health alone."

Masks will now be required for passengers on airlines, ships, railroads, and interstate buses; for people on federal lands and in federal properties and offices, such as post offices; and for federal employees and contractors. Television broadcasts showed staff at the White House all wearing masks, unlike at the Trump White House, where masks were rarely worn.

Travellers to the US will need to have a negative covid-19 test result before flying and must quarantine after arrival.

Biden named Anthony Fauci, the director of the National Institute of Allergy and Infectious Diseases, as his chief medical adviser. In a video conference call with Tedros Adhanom Ghebreyesus, director of the World Health Organization, Fauci announced that the US was rejoining WHO and would again give WHO financial support.

Biden also said the US was rejoining the Paris Climate Agreement.

At a White House briefing Fauci said, "The idea that you can get up here and talk about what you know, what the evidence, what the science is-let the science speak. It is somewhat of a liberating feeling."3

Susan Bailey, president of the American Medical Association, praised the Biden plan. In a statement she said, "Since March, the AMA has called on the federal government to implement a coordinated national strategy and pull every lever to ramp up PPE production for N95 masks, gowns, gloves, as well as testing supplies-and coordinate distribution. We commend the new administration for moving swiftly to implement a desperately needed national strategy."

The national covid-19 plan was organised around several goals. The first was to restore trust with the American people. The other goals were:

- To organise a comprehensive vaccination programme

- To reduce covid-19 spread by expanding masking, testing, data collection, treatments, and the healthcare workforce and setting clear public health standards

- To expand emergency relief and use the Defense Production Act to increase supplies of personal protective equipment

- To safely reopen schools, business, and travel while protecting workers

- To protect people most at risk and increase equity across racial, ethnic, and rural or urban lines, and

- To restore US leadership globally and prepare better for future threats by increasing the public health workforce.

In his plan Biden promised regular public briefings, led by experts and based on science, and reports on the state of the epidemic. He said the Centers for Disease Control and Prevention would develop clear, evidence based health guidance for the public and issue frequent updates.

The plan calls for the federal government to develop a safe, effective, and comprehensive vaccination campaign. Previously this was left to the states. The plan calls for improving allocation, distribution, administration, and tracking of vaccinations. It also calls for a campaign to build public trust in the importance of maintaining public health measures such as wearing masks, maintaining physical distancing, testing, and contact tracing.

Several states have reported short supplies of vaccines. Andrew Cuomo, governor of New York state, said the supply of first doses was running short. New York city, with more than eight million residents, rescheduled 23000 appointments because it expected to run out of first doses by 22 January. ${ }^{4}$

The Biden plan calls for setting up more sites for vaccinations in "settings that people trust," including community centres, stadiums, and conference centres in all 50 states and 14 territories. Vaccinations will also be available in pharmacies, retail stores, federal 
facilities such as the Veterans Affairs hospitals, community health centres, rural health clinics, critical access hospitals, doctors' offices, health systems, urgent care centres, and also mobile clinics and on-site occupational clinics.

The plan also calls for using the Defense Production Act to increase the manufacture of vaccines, personal protective equipment, and vaccination supplies such as bottles for the vaccine, stoppers, and injection syringes. The act requires businesses to prioritise materials needed for national defence.

1 National strategy for the covid-19 response and pandemic preparedness. https://www.whitehouse.gov/wp-content/uploads/2021/01/National-Strategy-for-the-COVID-19-Response-andPandemic-Preparedness.pdf.

2 Coronavirus in the US: latest map and case count. New York Times. 21 Jan 2021. https://www.nytimes.com/interactive/2020/us/coronavirus-us-cases.html.

3 Liptak K. Fauci talks “liberating feeling” serving under Biden versus Trump. CNN. 21 Jan 2021 https://www.cnn.com/2021/01/21/politics/anthony-fauci-trump-biden/index.html.

4 Millman J. Cuomo says NY 1st dose supply will empty in days; city forced to reschedule 23K appointments. NBC New York. 21 Jan 2021. https://www.nbcnewyork.com/news/coronavirus/nyhospitalizations-top-9k-for-1st-time-in-nearly-9-months-amid-vaccine-supply-fears/2839531. 